\title{
P 181 ACTION LEARNING AS A NOVEL APPROACH TO CHANGE CLINICAL PRACTICE
}

Fiona Hicks, ${ }^{1}$ Kathryn Winterburn, ${ }^{2}$ Annette Edwards ${ }^{3} .{ }^{1}$ Leeds Teaching Hospitals Trust, Leeds, England; ${ }^{2}$ Health Education Yorkshire and the Humber; ${ }^{3}$ Sue Ryder Wheatfields Hospice

\subsection{6/bmjspcare-2014-000654.222}

Background End-of-life care is essential to medical practice. Encouraging behavioural change in senior doctors who are trained to cure, and may see death as failure, is crucial to improving care and may benefit from novel approaches. Action Learning is a recognised tenet of management development but is rarely used within the education and development of doctors. Aim To evaluate the role of Action Learning as part of an end-of-life care development programme, bringing consultant colleagues together to encourage reflective practice, surface and resolve problems, share and consolidate learning.

Method This SHA funded pilot involved 2 trusts, each including 6 or 7 consultants and a GP. Both groups were facilitated by 2 consultants in palliative medicine, meeting monthly for 18 months. The programme was evaluated using training needs analyses at the beginning, middle and end, participant questionnaires asking for anonymous feedback and audits of practice and service developments. The 4 facilitators met together 6 weekly with a consultant in Organisational Development from the SHA in their own Action Learning Set and completed reflective diaries.

Results The use of action learning was highly valued by participants, many of whom had never previously met nor encountered this method of learning. The group provided an opportunity to discuss issues and "try out" difficult conversations in a challenging yet safe environment. Sets were very well attended, and regular meetings provided the impetus to complete agreed tasks.

Some facilitators initially struggled with the concept, but confidence grew during the learning process and as genuine peer learning enabled participants to help each other.

Discussion This pilot supported the idea that action learning can address learning needs and support behavioural change in senior doctors. This approach could be considered to address other areas within health care where organisational change is needed. 